\title{
Experiments and Computational Modeling of Pulverized- Coal Ignition
}

\author{
Semi-Annual Report \\ October 1, 1997 - March 31, 1998
}

\author{
By \\ John C. Chen
}

Work Performed Under Contract No.: DE-FG22-96PC96221

\author{
For \\ U.S. Department of Energy \\ Office of Fossil Energy \\ Federal Energy Technology Center \\ P.O. Box 880 \\ Morgantown, West Virginia 26507-0880 \\ By \\ North Carolina A\&T State University \\ Department of Mechanical Engineering \\ 1601 East Market Street \\ Greensboro, North Carolina 27411
}




\section{Disclaimer}

This report was prepared as an account of work sponsored by an agency of the United States Government. Neither the United States Government nor any agency thereof, nor any of their employees, makes any warranty, express or implied, or assumes any legal liability or responsibility for the accuracy, completeness, or usefulness of any information, apparatus, product, or process disclosed, or represents that its use would not infringe privately owned rights. Reference herein to any specific commercial product, process, or service by trade

name, trademark, manufacturer, or otherwise does not necessarily constitute or imply its endorsement, recommendation, or favoring by the United States Government or any agency thereof. The views and opinions of authors expressed herein do not necessarily state or reflect those of the United States Government or any agency thereof. 


\title{
EXPERIMENTS AND COMPUTATIONAL MODELING OF PULVERIZED-COAL IGNITION
}

\author{
Semi-Annual Technical Report \\ Reporting Period: 10/01/1997 through 03/31/1998 \\ Author: John C. Chen \\ Report Issue Date: 04/30/1998 \\ DE-FG22-96PC96221 - 04 \\ North Carolina A\&T State University \\ Department of Mechanical Engineering \\ 1601 East Market Street \\ Greensboro, NC 27411
}




\begin{abstract}
Under typical conditions of pulverized-coal combustion, which is characterized by fine particles heated at very high rates, there is currently a lack of certainty regarding the ignition mechanism of bituminous and lower rank coals. It is unclear whether ignition occurs first at the particle-oxygen interface (heterogeneous ignition) or if it occurs in the gas phase due to ignition of the devolatilization products (homogeneous ignition). Furthermore, there have been no previous studies aimed at determining the dependence of the ignition mechanism on variations in experimental conditions, such as particle size, oxygen concentration, and heating rate. Finally, there is a need to improve current mathematical models of ignition to realistically and accurately depict the particle-to-particle variations that exist within a coal sample. Such a model is needed to extract useful reaction parameters from ignition studies, and to interpret ignition data in a more meaningful way.
\end{abstract}

We propose to examine fundamental aspects of coal ignition through (1) experiments to determine the ignition mechanism of various coals by direct observation, and (2) modeling of the ignition process to derive rate constants and to provide a more insightful interpretation of data from ignition experiments.

We propose to use a novel laser-based ignition experiment to achieve our objectives. The heating source will be a pulsed, carbon-dioxide $\left(\mathrm{CO}_{2}\right)$ laser in which both the pulse energy and pulse duration are independently variable, allowing for a wide range of heating rates and particle temperatures - both of which are decoupled from each other and from the particle size. This level of control over the experimental conditions is truly novel in ignition and combustion experiments. Laser-ignition experiments also offer the distinct advantage of easy optical access to the particles because of the absence of a furnace or radiating walls, and thus permit direct observation and particle temperature measurement. The ignition mechanism of different coals under various experimental conditions can therefore be easily determined by direct observation with high-speed photography. The ignition rate-constants, when the ignition occurs heterogeneously, and the particle heating rates will both be determined from analyses based on direct, particle-temperature measurements using two-color pyrometry.

For the modeling portion of this study we will complete the development of the Distributed Activation Energy Model of Ignition (DAEMI), which simulates the conventional drop-tube furnace ignition experiment. The DAEMI accounts for particle-to-particle variations in reactivity 
by having a single preexponential factor and a Gaussian distribution of activation energies among the particles. Previous results show that the model captures the key experimental observations, and that adjustments to the model parameters permit a good fit to experimental data. We will complete the model by (1) examining the effects of other variations in physical parameters on the model, (2) applying the model to published results in order to extract reaction parameters, and (3) extending the model for application to laser-based ignition studies, such as our own.

\section{Table of Contents}

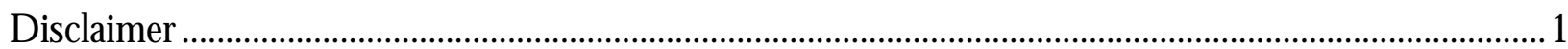

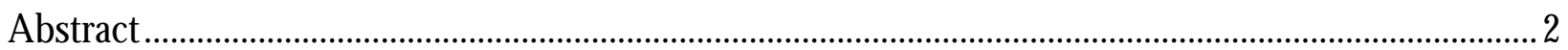

Table of Contents..........................................................................................................................

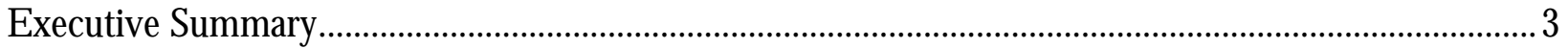

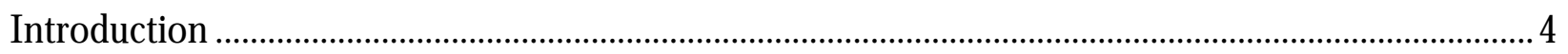

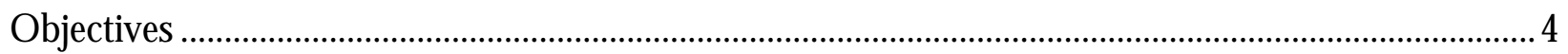

Results from This Reporting Period and D iscussion.........................................................................

Computational Model.......................................................................................................................

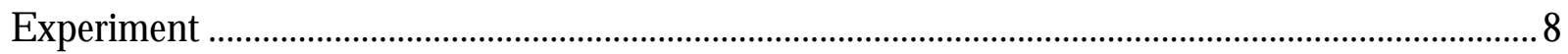

Meetings and Conferences ........................................................................................................ 13

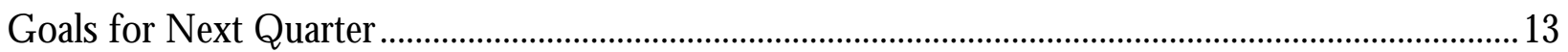

\section{Executive Summary}

D uring the past reporting period, modified the DAEMI to examine two aspects of ignition modeling: (1) the model was modified to examine the effect of varying number of particles chosen to interact with the laser, and (2) the incorporation of a size distribution into the model. The results showed that the model is sensitive to the number of particles interacting with the laser and that, therefore, it may be necessary to experimentally determine the number of particles for each experimental run. This might be done, for example, by calibrating the detector signal level against the observed number of particles interacting with the laser pulse. The observation can be accomplished using the high-speed video camera. Results obtained by incorporating a particle size distribution have little effect on the model results.

D uring the past reporting period we have focused on two fronts to make progress in the laboratory studies. First, the two-wavelength pyrometry system, described fully in the prior 
progress report, has been modified to eliminate a measurement error. Second, we have successfully calibrated the pyrometer and used it to make the first measurements of ignition temperatures in this experiment.

\section{Introduction}

The ignition of pulverized coal has been the subject of research for nearly 150 years, with the initial motivation being the avoidance of coal-dust explosions in mines. In more recent times, due to the world's increased reliance on coal for power generation and the need to maximize energyconversion efficiency, research has shifted to understanding the fundamental mechanism of coal ignition and measuring its kinetic rates. The importance of ignition to coal-flame stability is obvious - the more easily a particular coal ignites after injection into a boiler furnace, the better its flamestability characteristics. A less obvious ramification of the ignition process is its role in establishing extended, fuel-rich zones in coal flames which are responsible for the destruction of NOx and its conversion to benign $\mathrm{N}_{2}$. Certainly, the ignition process is inextricably linked to the formation of this NOx-reduction zone, and the ignition behavior of coals and coal blends will strongly affect the ease and extent of formation of this zone. This connection is deserving of further study and its understanding is the goal toward which we hope to apply the results of this proposed study. Specifically, we propose to examine fundamental aspects of coal ignition through (1) experiments to elucidate the ignition behavior of coals, and (2) modeling of the process to derive accurate and useful rate constants, and to provide a more insightful interpretation of data from ignition experiments.

\section{O bjectives}

O ur objectives for this project are to:

1. develop a novel experimental facility with extensive optical-diagnostic capabilities to study coal ignition;

2. determine the ignition mechanism of coals under simulated combustion conditions by direct observation with high-speed photography;

3. examine the effects of various experimental conditions, including coal rank, particle size, oxygen concentration and heating rate, on the ignition mechanism; and

4. measure the ignition rate constants of various coals.

5. modify our existing ignition model to examine the effect of particle-size distribution on the ignition behavior; 
6. incorporate, if necessary, a size distribution into the model;

7. apply the model to extract ignition rate constants from previously published data from conventional experiments;

8. modify the model and apply it to our laser-based ignition studies for determination of ignition rate constants.

\section{Results from This Reporting Period and D iscussion}

D uring the past reporting period, we have made excellent progress on both the modeling and experiment portion of this project. We are currently preparing two manuscripts for submission and possible publication. The first, "The Ignition Behavior of Pulverized Coals," concerns mainly the experimental measurements that we have obtained, and interprets these measurements in terms of the model in its current form. The second manuscript, "Modeling the Ignition of Pulverized Coals," will focus on the current modifications to the Distributed Activation Energy Model of Ignition (DAEMI) which we are in the process of implementing, along with some supporting experimental measurements.

\section{Computational Model}

D uring the past reporting period, modified the DAEMI to examine two aspects of ignition modeling: (1) the model was modified to examine the effect of varying number of particles chosen to interact with the laser, and (2) the incorporation of a size distribution into the model. These results will be discussed in turn.

Figure 1 shows the predicted ignition frequency using either a value of one particle $(M=1)$ or a value of three particles $(M=3)$ to be the number of particles chosen to interact with the laser pulse. The other parameters of the model are shown in the following table:

\begin{tabular}{|l|c|}
\hline Gas temperature, $\mathrm{K}$ & 300 \\
\hline Reaction order & 1.0 \\
\hline Particle size range, $\mu \mathrm{m}$ & $125-150$ \\
\hline Preexponential factor $\left(\mathrm{A}_{\mathrm{o}}\right), \mathrm{kg} /\left(\mathrm{m}^{2} \mathrm{~s}\right)$ & 250 \\
\hline Average activation energy $\left(\mathrm{E}_{\mathrm{o}}\right), \mathrm{kJ} / \mathrm{mol}$ & 58.0 \\
\hline Standard deviation of activation energy $(\mathrm{s}), \mathrm{kJ} / \mathrm{mol}$ & 5.5 \\
\hline
\end{tabular}

The particle size in this case is assumed to be constant, and is the average of the particle size range $(138 \mu \mathrm{m})$. The oxygen concentration is varied, as shown in the figure caption. 


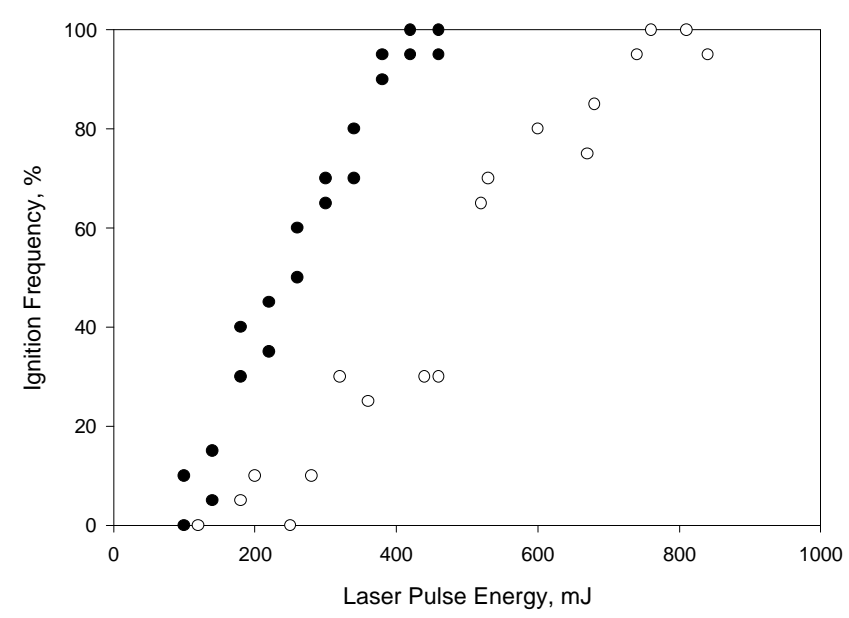

Figure 1: Calculated ignition frequencies for conditions shown in Table in text above. Oxygen concentration is $100 \%$. The OPEN symbols are for $M=1$, and the FILLED symbols are for $\mathrm{M}=3$.

Figure 2 below shows the calculated ignition frequency distribution for particles of the same size range $(125-150 \mu \mathrm{m})$, but with an oxygen concentration of $75 \%$; all other parameters are as shown in the Table above.

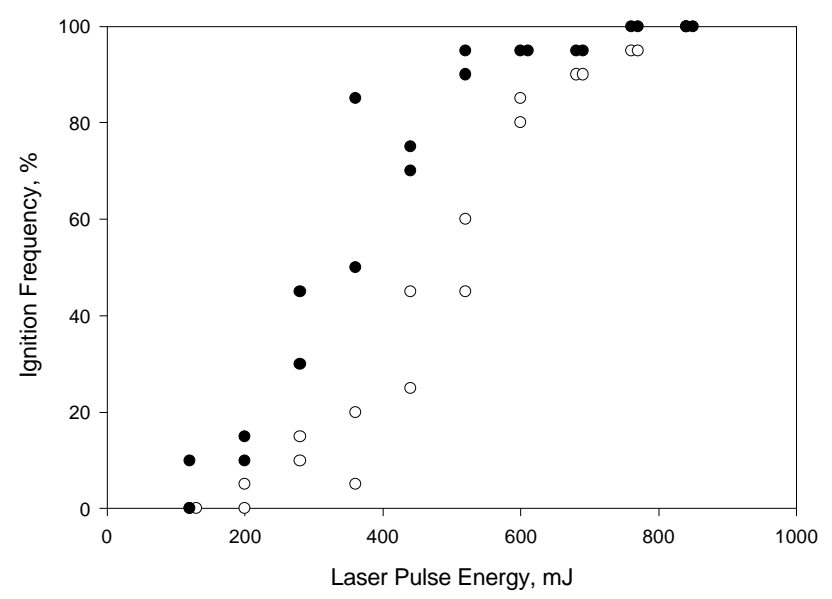

Figure 2: Calculated ignition frequencies for conditions shown in Table in text above. Oxygen concentration is $75 \%$. The $\mathrm{OPEN}$ symbols are for $\mathrm{M}=1$, and the FILLED symbols are for $\mathrm{M}=3$.

It can be seen from the figures above that the results, while exhibiting the observed experimental behavior of monotonically increasing ignition frequency with increasing laser energy, are sensitive to the value of $\mathrm{M}$. This suggests, therefore, that it may be necessary to experimentally determine the value of $\mathrm{M}$ for each experimental run. This might be done, for example, by calibrating the detector signal level against the observed number of particles interacting with the 
laser pulse. The observation can be accomplished using the high-speed video camera. Figures 1 and 2 represent particles of size range 125-150 $\mu \mathrm{m}$. Similar results are found for 150-180 $\mu \mathrm{m}$ particles (Fig. 3 (a) and (b)).

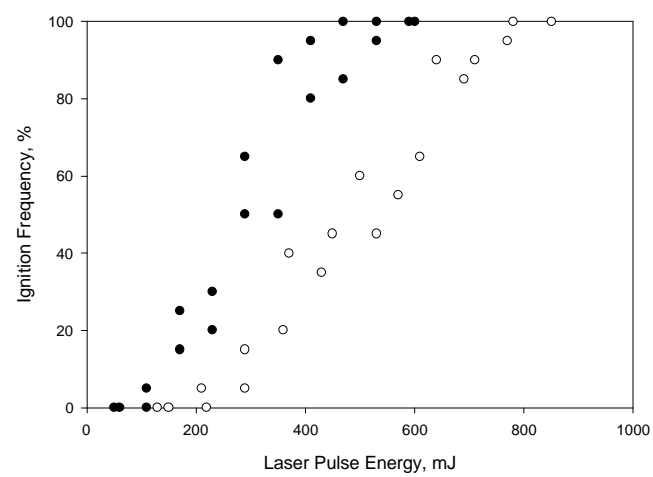

(a)

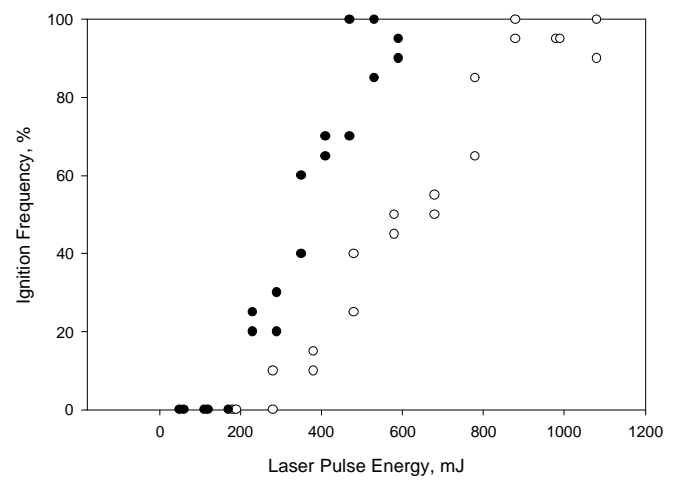

Figure 3: Ignition frequency distributions for 150-180 $\mu$ m particles. (a) $100 \%$ oxygen concentration, (b) 67\% oxygen concentration. All other parameters are shown in Table in text above. The OPEN symbols are for $M=1$, and the FILLED symbols are for $\mathrm{M}=3$.

The second modification made during the last reporting period was to incorporate a distribution in particle sizes into the model. This was accomplished by dividing the particle size range (125 to $150 \mu \mathrm{m}$, for example) into 1- $\mu \mathrm{m}$ 'bins.' All particles of a particular size range is then assumed to be equally distributed among these $1-\mu \mathrm{m}$ bins. That is, it is assumed that the particles have equal probabilities of being in any particular size bin. The equal or 'top hat' distribution of particle sizes is justified given that sized coal particles typically follow a log-normal distribution among all coal sizes and, over a narrow size range, it is reasonable to assume an equal distribution of sizes.

The model is then run and, as before, all $4 \times 10^{5}$ particles in the original batch are normally distributed in activation energy. For each simulated experimental run, 1300 particles are randomly chosen as those which are dropped into the test section and, of these, $\mathrm{M}$ number are chosen as the ones that interact with the laser. These $\mathrm{M}$ particles are randomly assigned a particle size from its size range, and the model calculates the ignition temperature and ignition frequency, as before.

The results of the ignition frequency distribution for 150-180 $\mu \mathrm{m}$ particles are shown in Fig. 4. These results should be compared to Fig. 3(a) above, and it can be seen that incorporating a particle size distribution has little effect on the model results. 


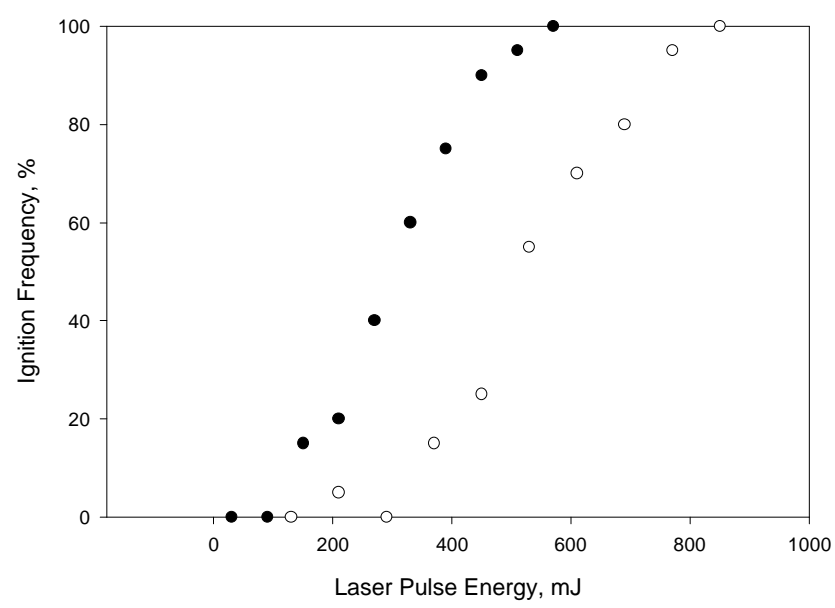

Figure 4: $\quad$ DAEMI results after incorporating a particle size distribution. The results should be compared to Fig. 3(a), which assumes a constant, average particle size. The OPEN symbols are for $\mathrm{M}=1$, and the FILLED symbols are for $\mathrm{M}=3$.

Figure 5 shows the calculated particle ignition temperature as a function of the laser pulse energy corresponding to the case of $M=1$ from Fig. 4. Superimposed on the figure is the ignition frequency distribution. It can be seen that the model, with the incorporated size distribution, predicts that there exists a distribution in ignition temperature at each laser energy, due to the varied particle sizes. Furthermore, as laser pulse energy increases, the ignition temperature also increases, on average.

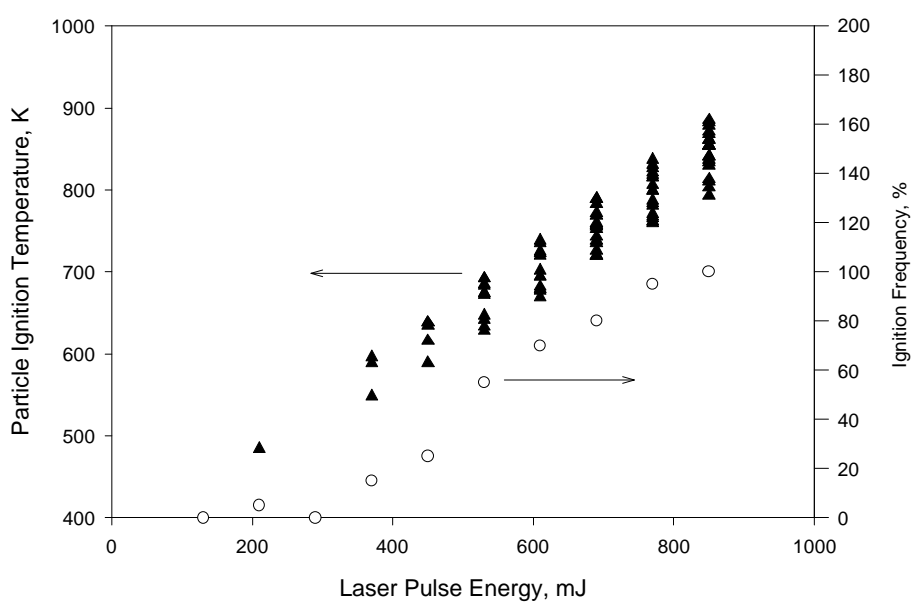

Figure 5: Calculated particle ignition temperatures as a function of laser pulse energy.

\section{Experiment}

During the past reporting period we have focused on two fronts to make progress in the laboratory studies. First, the two-wavelength pyrometry system, described fully in the prior progress report, has been modified to eliminate a measurement error. Second, we have successfully 
calibrated the pyrometer and used it to make the first measurements of ignition temperatures in this experiment.

The measurement error introduced by the original version of the two-wavelength pyrometry system was discovered during data reduction of ignition temperature measurement. An example of the error encountered is shown in Fig. 6, which shows the signal traces from each of the two detectors in the pyrometry system over the entire observed time (a) and in the short time around the ignition point (b). In reference to Fig. 6(b), the error is clearly seen in the mismatch of the minima of the signal traces. It is expected, and indeed theoretically accurate, that as the particle temperature traverses through a minimum, then the light emitted by the particle at any wavelengths must also traverse through minima. 


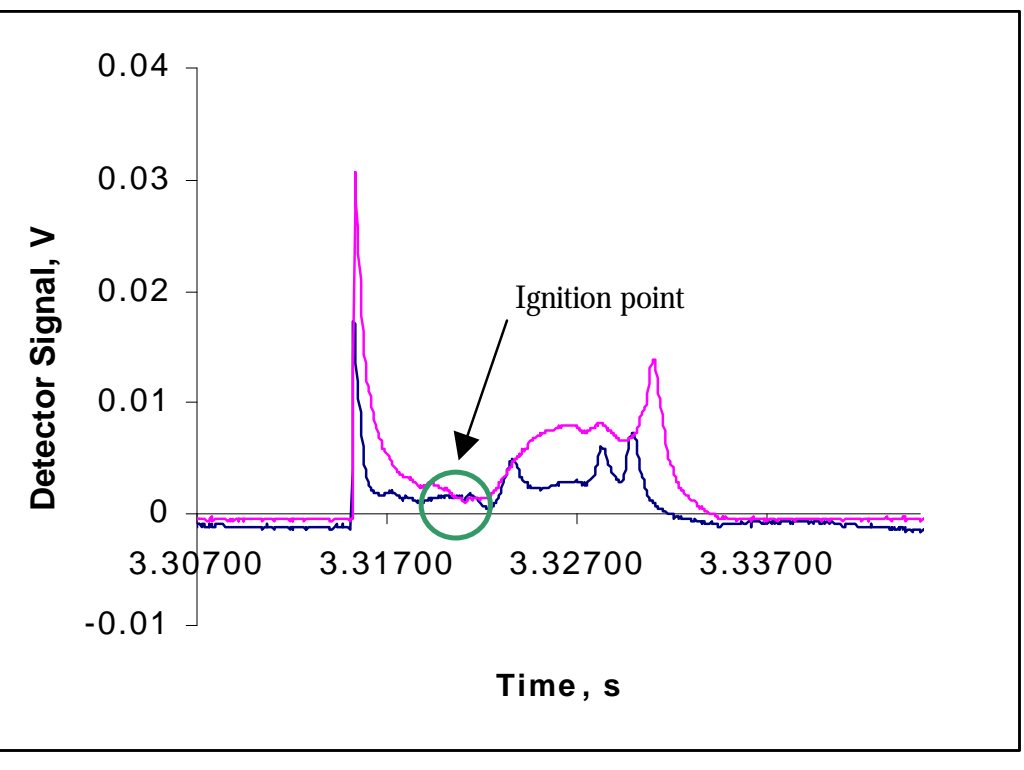

(a)

(b)

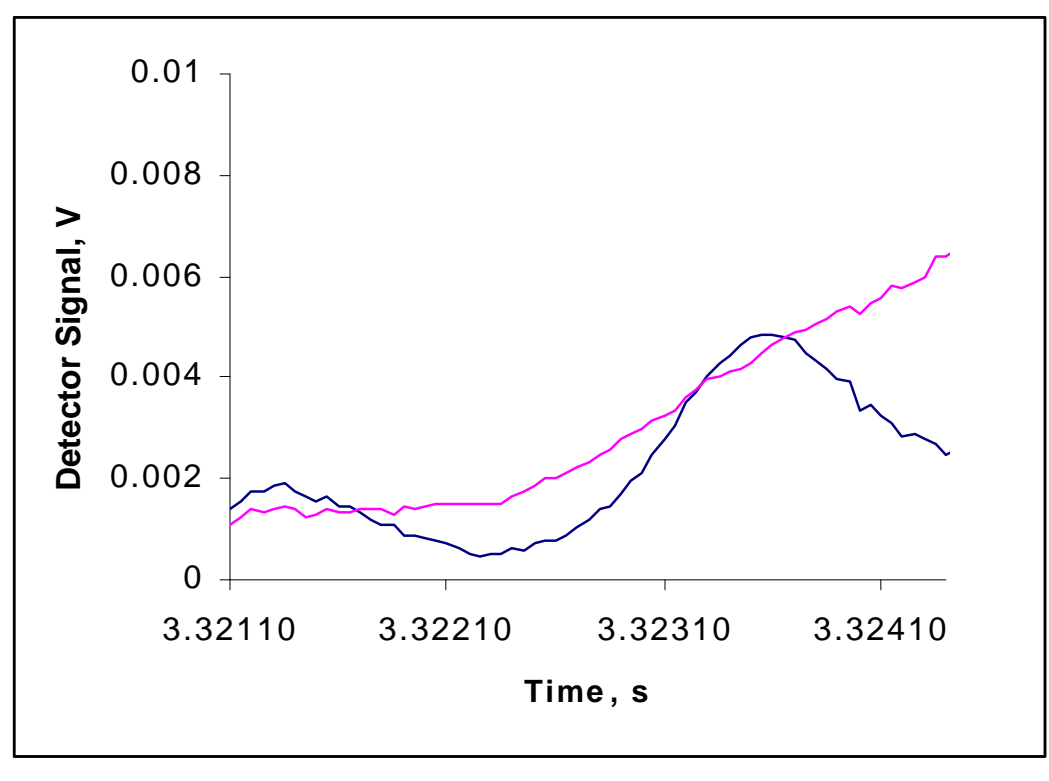

Figure 6: Signal traces of two detectors observing a single igniting coal particle at two different wavelengths. (a) Signal trace during entire observed time; (b) expanded view of signal trace at ignition point of (a). Note the misalignment in time of the two signals.

The optical fiber bundle used in the original pyrometry system caused the observed error. The igniting particle was imaged onto the fiber bundle via a simple lens. The fiber bundle is trifurcated (separated into three separated light paths) by splitting the bundle at the head into three smaller bundles. Two of the three trifurcated legs directed their light through lenses and bandpass filters, and ultimately onto photodetectors (the third leg was not used). The error occurred since the particle image was approximately the same size as a single fiber which makes up the bundle. 
Thus, in nearly every case, the detectors did not similtaneausyobserve the igniting particle(s), but rather observed them with a slight time offset, producing the signal traces typified in Fig. 6 .

The new pyrometry system is shown in Fig. 7. The trifurcated optical fiber bundle is replaced by a single bundle, thus avoiding the prior problem. Also, the captured light from the igniting particles is split using a dichroic beamsplitter, which actually improves the signal level compared with the original system, albeit at the expense of a more difficult beam alignment. It can be seen in Fig. 8 that the error seen in Fig. 6 has been eliminated with the new system.

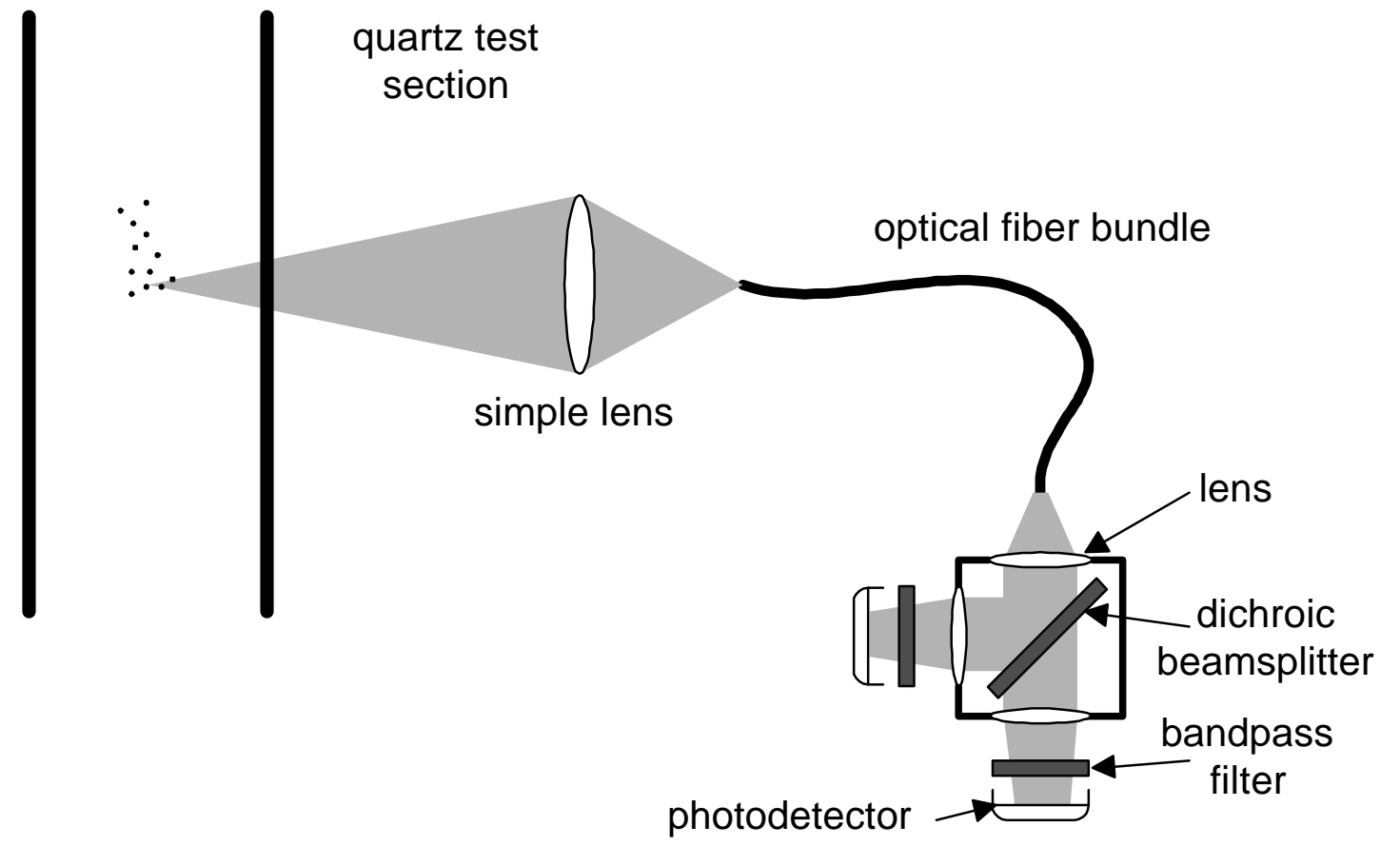

Figure 7: New two-wavelength pyrometry system which eliminates the experimental error of the original set-up. 


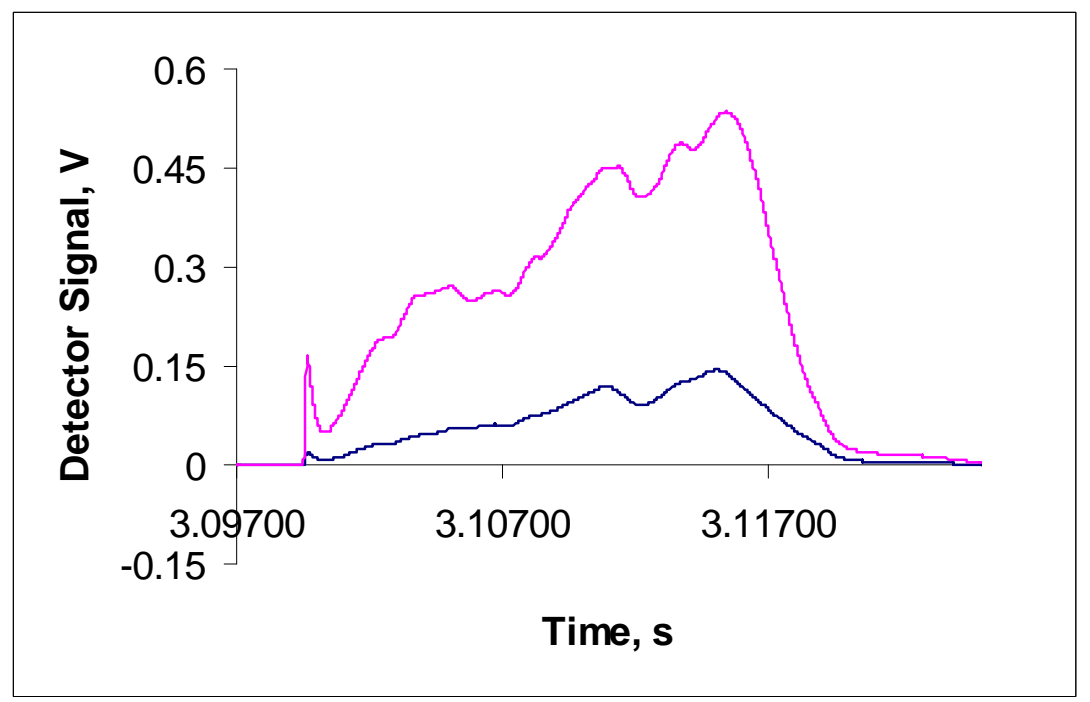

Figure 8: Typical detector traces using the new pyrometry set-up. Note that the two signals are now aligned in time.

We have begun using the new pyrometry system to measure ignition temperatures along with measurement of ignition frequency. The data for one coal, Pittsburgh \#8 high-volatile bituminous, is nearly complete. The ignition frequency distribution of this coal at $100 \%$ and $67 \%$ oxygen using a particle size of 150-180 $\mu \mathrm{m}$ is shown in Fig. 9. The measured distribution of ignition temperatures for the same conditions is shown in Fig. 10.

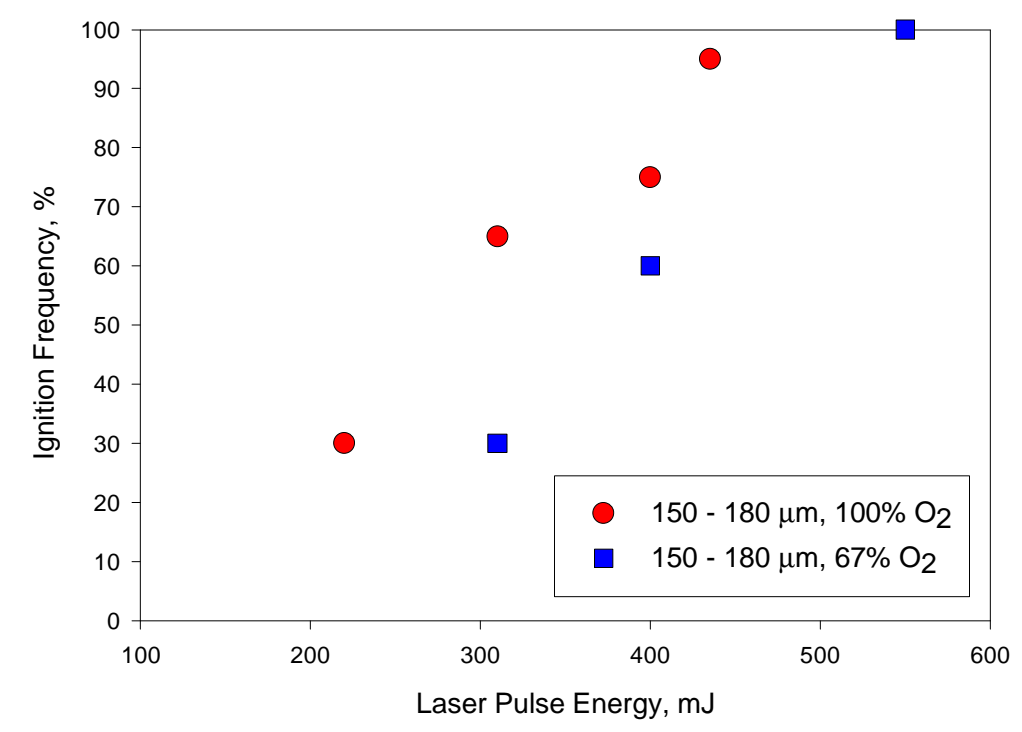

Figure 9: Ignition frequency distribution for Pittsburgh \#8 hvb coal, 150-180 $\mu \mathrm{m}$ in size, and $100 \%$ or $67 \%$ oxygen concentration. 


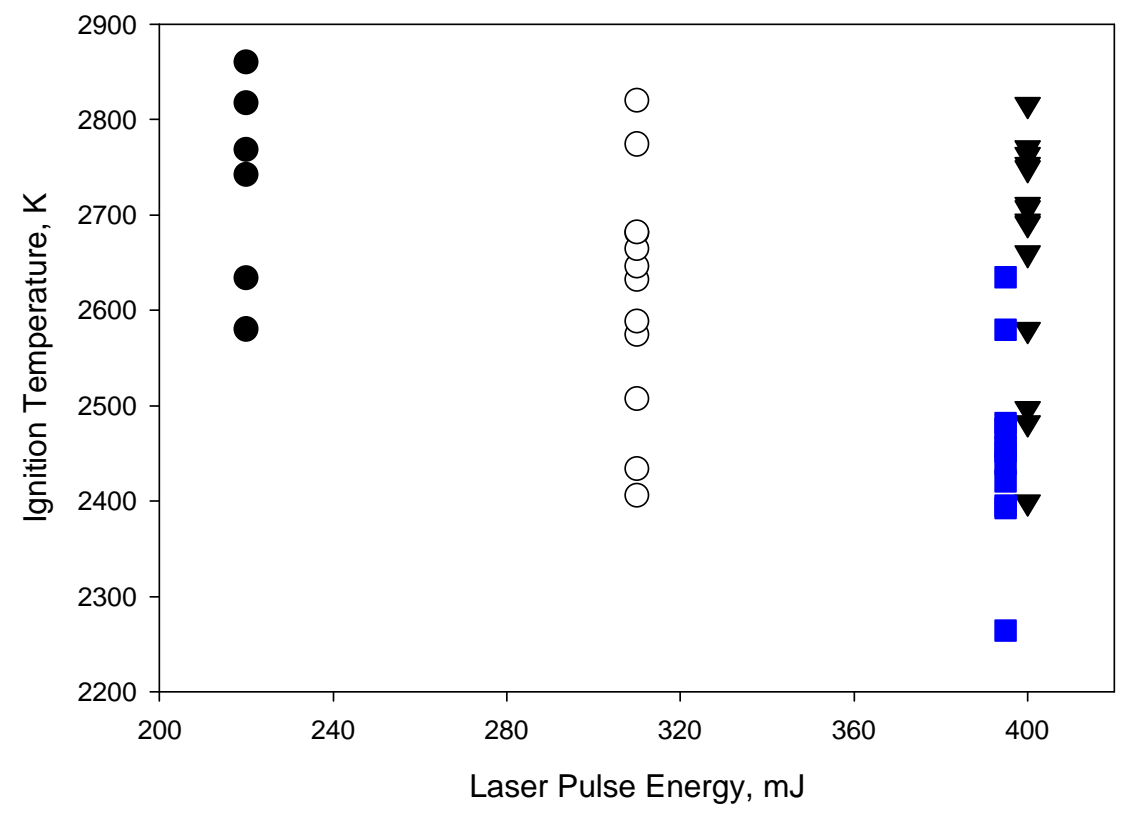

Figure 10: Measured ignition temperatures during ignition for Pittsburgh \#8 hvb coal, 150-180 $\mu \mathrm{m}$ in size. Data represented by squares correspond to an oxygen concentration of $67 \%$, and the remaining data are at $100 \%$ oxygen.

\section{Meetings and Conferences}

The results discussed in this report were recently presented at the Spring 1998 National Meeting of the American Chemical Society, Fuel Chemistry Division. The Meeting was held March 29 to April 2, 1998, in Dallas, Texas. O ur paper was selected for a special presentation the Sci-Mix poster session, and was also nominated for the Glenn Award, the Fuel Chemistry Division's Best Paper A ward.

\section{G oals for N ext Q uarter}

D uring the next reporting period, we will complete the measurement of ignition temperatures of various coals. We plan to make measurements for a suite of five coals: a lignite, a subbituminous, a high-volatiles bituminous, a medium-volatile bituminous, and a low-volatile bituminous. The experimental conditions will cover three oxygen concentrations and four particle size-cuts. Concurrent with these measurements will be the capturing of the ignition and combustion sequences using a high-speed video camera. The video sequences will elucidate the ignition mechanism for each coal under typical pulverized-coal combustion conditions. Finally, we will further modify and refine the Distributed Activation Energy Model of Ignition in order to infer, rather than assume, the preexponential factor in the Arrhenius rate constant. The model will be 
applied to the experimental measurements of ignition temperature to determine ignition rate constants for various coals, and these results will be compared to conventional rate constants determined assuming an average value for the activation energy. 